\title{
Histopathological and Ultrastructural Alterations in Anabas testudineus Exposed to Glyphosate-Based Herbicide, Excel Mera 71 under Field and Laboratory Conditions
}

Palas Samanta ${ }^{1,2}$, Sandipan Pal ${ }^{3}$, Aloke Kumar Mukherjee ${ }^{4}$, Tarakeshwar Senapati ${ }^{1}$ and Apurba Ratan Ghosh ${ }^{\text {** }}$

${ }^{1}$ Ecotoxicology Lab, Department of Environmental Science, The University of Burdwan, Golapbag, West Bengal, India ${ }^{2}$ Division of Environmental Science and Ecological Engineering, Korea University, Anam-dong, Sungbuk-gu, Republic of Korea ${ }^{3}$ Department of Environmental Science, Aghorekamini Prakash Chandra Mahavidyalaya, Subhashnagar, Bengal, West Bengal, India ${ }^{4}$ Department of Conservation Biology, Durgapur Govt. College, West Bengal, India

\begin{abstract}
Present study aimed to investigate the effects of glyphosate-based herbicide, Excel Mera 71 on histopathological and ultrastructural changes in freshwater teleostean fish, Anabas testudineus (Bloch) under field (750 g/acre) and laboratory $(17.20 \mathrm{mg} / \mathrm{l})$ conditions for 30 days. In field experiment, fish were reared in special type of cage submerged in pond. Cellular alterations in stomach and intestine were observed through light, scanning and transmission electron microscopy (SEM and TEM). Lesions at the cellular and subcellular levels under field and laboratory conditions were compared. Responses under light microscopy depicted that the symptoms of lesions were more pronounced under laboratory condition than field. Ultrastructural examination also confirmed the observations through SEM and TEM study and the degree of responses in concerned tissues were different under these two conditions. Therefore, evaluation of these histopathological lesions in the concerned tissues may be established as symptomatic indicators for toxicity study in aquatic ecosystem.
\end{abstract}

Keywords: Anabas testudineus; Glyphosate; Histopathology; Ultrastructure

\section{Introduction}

Aquatic pollution by pesticides and/or herbicides, either through run-off from agricultural land, or by direct applications such as spray drift, aerial spraying and by discharge as effluents from manufacturing industries, is recognized as strong biological poisons. Now, it becomes a threat to non-target aquatic organisms such as fin-fish and shellfish [1]. Now-a-days, the application of herbicides into the aquatic bodies increases several folds to control the invasive plant species such as water hyacinth and hydrilla etc. Glyphosate is the most effective modern third generation, broad-spectrum herbicide and widely used both in agriculture and paddy-cum-fish-culture system in recent times. It is a non-selective, cost- effective and post-emergence herbicide [2]. Glyphosate is a weak organic acid; its chemical name is $\mathrm{N}$-(phosphonomethyl) glycine. Glyphosate is soluble in water (12 $\mathrm{g} / \mathrm{l}$ at $25^{\circ} \mathrm{C}$ ) but insoluble in most organic solvents [3]. Glyphosate is readily degraded both from water and soil by soil microbes to aminomethylphosphonic acid (AMPA) and carbon dioxide $\left(\mathrm{CO}_{2}\right)[4]$. Due to strong adsorptive characteristics, glyphosate and AMPA are not likely to move to groundwater but have the potency to contaminate surface water. Glyphosate is in the toxicity class of III (on I to IV scale, where IV is least dangerous) for oral and inhalation exposure [5].

Cytopathological study provides a fast and efficient process to delineate the health status of organisms exposed to xenobiotic substances. Currently, histopathological biomarkers are used extensively for documenting and quantifying exposure level, as well as expressing the effects of environmental stressors. A number of studies on histopathological biomarkers in the evaluation of fish health exposed to contaminants, both in the laboratory and field studies were reported [6-8]. The major advantages of using histopathological biomarkers in environmental monitoring are that they allow the investigation of specific target organ toxicity including stomach, intestine etc., as well as quantification of pollutants that are biologically available and finally help in the elucidation of mechanisms of action. Stomach and intestine in the present study as important parts of alimentary canal are playing a vital role in final metabolism of orally administered toxic materials directly. They are also exposed indirectly via blood and/or lymph. Furthermore, the alterations observed in these organs are normally easier to identify the functional ones [9]; and serve as warning signals of damage to animal health [10].

Considering the extensive use of this herbicide by the farmers for the agricultural purposes as in one hand and the scarce knowledge on side effects on air-breathing teleost, Anabas testudineus in field condition on other hand, the objectives of the present investigation are to characterise and evaluate the histopathological and microanatomical alterations through scanning and transmission electron microscopic observations in the stomach and intestine of Anabas testudineus. In addition, for further monitoring of the toxic effects this fish were exposed to high herbicide concentration under laboratory condition. Furthermore, we have been able to assess the usefulness of these parameters as biomarkers against Excel Mera 71 exposure and to determine some indicators in fish toxicology.

\section{Materials and Methods}

Freshwater teleostean fish, Anabas testudineus (Bloch) of both the sexes with an average weight of $16.09 \pm 1.420 \mathrm{~g}$ and total length of 10.09 $\pm 0.251 \mathrm{~cm}$ were procured from the local market and were acclimatized under laboratory condition for 15 days in aquaria of $250 \mathrm{~L}$ capacity.

*Corresponding author: Apurba Ratan Ghosh, Ecotoxicology Lab, Department of Environmental Science, The University of Burdwan, Golapbag, Burdwan 713104 West Bengal, India, Tel: +91-342-2657938; E-mail: apurbaghosh2010@gmail.com

Received June 30, 2016; Accepted July 28, 2016; Published July 30, 2016

Citation: Samanta P, Pal S, Mukherjee AK, Senapati T, Ghosh AR (2016) Histopathological and Ultrastructural Alterations in Anabas testudineus Exposed to Glyphosate-Based Herbicide, Excel Mera 71 under Field and Laboratory Conditions. J Aquac Res Development 7: 436. doi:10.4172/2155-9546.1000436

Copyright: (c) 2016 Samanta P, et al. This is an open-access article distributed under the terms of the Creative Commons Attribution License, which permits unrestricted use, distribution, and reproduction in any medium, provided the original author and source are credited. 
Citation: Samanta P, Pal S, Mukherjee AK, Senapati T, Ghosh AR (2016) Histopathological and Ultrastructural Alterations in Anabas testudineus Exposed to Glyphosate-Based Herbicide, Excel Mera 71 under Field and Laboratory Conditions. J Aquac Res Development 7: 436. doi:10.4172/2155-9546.1000436

Fish were kept in continuously aerated water with a static system under natural photoperiod of 12-h light/12-h dark. After acclimatization, fish were divided into two groups: one group was transferred to field ponds located at Crop Research and Seed Multiplication Farm (CRSMF) premises of the University of Burdwan and other group was transferred to departmental laboratory aquarium. Fish were fed once a day with commercial fish pellets (32\% crude protein, Tokyu) during both acclimatization and exposure periods.

For field experiment, fish were allocated in two groups as follows: control groups with 10 fish in three separate cages in control pond, and exposure groups with 10 fish in separate cages (triplicate) for 30 days in treatment pond. Two ponds are close to each other. The desired dose of $750 \mathrm{~g} /$ acre corresponds to concentration recommended for use in rice culture was dissolved in water and applied once. It was sprayed on the first day of the experiment on the surface of each cage of glyphosate-treated plots in treatment pond. Glyphosate concentration in water was monitored according to Jan et al. [11] during 30 days and it was $1.20 \pm 0.47 \mathrm{mg} / \mathrm{l}$. Raw water sample $(\mathrm{n}=6)$ are taken for analysis of glyphosate concentration. For field experiment a special type of cage was prepared and installed separately at pond of CRSMF as per Chattopadhyay et al. [12] with some modifications. All the cages were square in shape having an area of $2.5 \mathrm{~m} \mathrm{x} 1.22 \mathrm{~m}$ and height of the cage was $1.83 \mathrm{~m}$ (submerged height was $0.83 \mathrm{~m}$ ). Cages were framed by light, strong bamboo. The four-sided wall, floor of the cage and top of the cage covers were fabricated with nylon net and were embraced by two PVC nets: the inner and outer bearing mesh sizes of $1.0 \times 1.0$ $\mathrm{mm}^{2}$ and $3.0 \times 3.0 \mathrm{~mm}^{2}$ respectively. Cages were placed at the middle of each pond. During the experimentation period (30 days) in the field, pond water was measured as per APHA [13] had the following average values: temperature, $24.03 \pm 0.203^{\circ} \mathrm{C} ; \mathrm{pH}, 6.56 \pm 0.087$; electrical conductivity, $347.00 \pm 1.15 \mu \mathrm{S} / \mathrm{cm}$; total dissolved solids, $247.67 \pm 1.45$ $\mathrm{mg} / \mathrm{l}$; dissolved oxygen, $7.00 \pm 0.157 \mathrm{mg} / \mathrm{l}$; total alkalinity, $221.33 \pm 3.53$ $\mathrm{mg} / \mathrm{l}$ as $\mathrm{CaCO}_{3}$; total hardness, $140.00 \pm 2.31 \mathrm{mg} / \mathrm{l}$ as $\mathrm{CaCO}_{3}$; sodium, $63.40 \pm 2.67 \mathrm{mg} / \mathrm{l} ;$ potassium, $15.96 \pm 2.10 \mathrm{mg} / \mathrm{l}$; orthophosphate, 0.24 $\pm 0.026 \mathrm{mg} / \mathrm{l}$; ammoniacal-nitrogen, $0.74 \pm 0.111 \mathrm{mg} / \mathrm{l}$; and nitratenitrogen, $1.66 \pm 0.035 \mathrm{mg} / \mathrm{l}$.

In case of laboratory experiment, fish were divided into two groups (control and glyphosate-treated) and maintained in six aquaria, containing 10 fish in each aquarium: three for control and another three for treatment. Fish were exposed to sub-lethal dose of glyphosate, i.e., $17.20 \mathrm{mg} / \mathrm{l}\left(20 \%\right.$ of the $96 \mathrm{~h} \mathrm{LC}_{50}$ value in Oncorhynchus mykiss i.e., $86 \mathrm{mg} / \mathrm{l}$ [14]) in $40 \mathrm{~L}$ aquaria for a period of 30 days [15,16]. Dose was applied for every alternate day. Glyphosate concentration in water was $16.88 \pm 1.69 \mathrm{mg} / \mathrm{l}$. Normal tap water with proper aeration and dechlorination (at least $48 \mathrm{~h}$ before use) was used for this experiment. During experimentation period, the average water parameters were measured as follows: temperature, $26.63 \pm 0.120^{\circ} \mathrm{C} ; \mathrm{pH}, 7.93 \pm 0.075$; electrical conductivity, $426.00 \pm 5.93 \mu \mathrm{S} / \mathrm{cm}$; total dissolved solids, $302.89 \pm 4.69 \mathrm{mg} / \mathrm{l}$; dissolved oxygen, $5.06 \pm 0.43 \mathrm{mg} / \mathrm{l}$; total alkalinity, $209.80 \pm 10.50 \mathrm{mg} / \mathrm{l}$ as $\mathrm{CaCO}_{3}$; total hardness, $163.11 \pm 3.04 \mathrm{mg} / \mathrm{l}$ as $\mathrm{CaCO}_{3}$; sodium, $37.76 \pm 1.02 \mathrm{mg} / \mathrm{l}$; potassium, $7.26 \pm 1.12 \mathrm{mg} / \mathrm{l}$; orthophosphate, $0.04 \pm 0.002 \mathrm{mg} / \mathrm{l}$; ammoniacal-nitrogen, $7.09 \pm 2.15$ $\mathrm{mg} / \mathrm{l}$; and nitrate-nitrogen, $1.78 \pm 0.263 \mathrm{mg} / \mathrm{l}$.

After completion of the experiment, five individual fish from each cage of both the control and treatment were collected followed by dissection, and tissues namely stomach and intestine were then fixed in aqueous Bouin's fluid solution for histological study, followed by dehydration through ethanol and finally embedded in paraffin. Paraffin sections were cut at $3-4 \mu \mathrm{m}$ using Leica RM2125 microtome. Finally, sections were stained with haematoxylin-eosin (H\&E) and observed under Leica DM2000 light microscope.

For scanning electron microscopic (SEM) study, tissues from remaining fish were fixed in $2.5 \%$ glutaraldehyde in phosphate buffer $(0.2 \mathrm{M}, \mathrm{pH} 7.4)$ for $24 \mathrm{~h}$ at $4^{\circ} \mathrm{C}$ and then post-fixed with $1 \%$ osmium tetraoxide for $2 \mathrm{~h}$ at $4^{\circ} \mathrm{C}$, dehydrated through graded acetone, subsequently followed by amyl acetate and subjected to critical point drying (CPD) with liquid carbon dioxide. Tissues were then mounted and sputter-coated with gold and finally examined under scanning electron microscope (Hitachi S-530) at University Science Instrumentation Centre of the University of Burdwan, West Bengal, India. For transmission electron microscopic (TEM) study, tissues were fixed in Karnovsky fixative for $12 \mathrm{~h}$ at $4^{\circ} \mathrm{C}$ and then post-fixed with $1 \%$ osmium tetraoxide for $2 \mathrm{~h}$ at $4^{\circ} \mathrm{C}$, dehydrated through graded acetone, infiltrated and embedded in epoxy resin. Ultrathin sections were cut by using a glass knife, collected on naked copper-meshed grids, and contrasted with uranyl acetate and lead citrate. Finally tissues were examined under TECHNAI G2 high resolution transmission electron microscope at Electron Microscope Facility, Department of Anatomy, AIIMS, New Delhi, India.

\section{Results and Discussion}

Figure 1.1 showing control stomach of $A$. testudineus which is made up of as usual of four histological layers viz., mucosa, submucosa, muscularis and serosa, and gastric mucosa is lined with a single layer of compactly arranged columnar epithelial cells with centrally placed nuclei. The tubular as well as rounded gastric glands are also present at basal portion of gastric mucosa of the cardiac stomach (Figure 1.1). The most conspicuous changes in stomach after glyphosate exposure in the laboratory condition were damage in gastric epithelium which became elongated, vacuolated and detached from the lamina propria of gastric folds (Figure 1.2), while except partial fusion of mucosal folds no significant alterations in the gastric epithelium was observed in stomach under field condition (Figure 1.3)

Ultrastructural alterations as viewed under SEM study also confirmed the severe topological alterations in stomach (Figure 1.4) such as severe damage in epithelial cells which included fragmentation, damage in microridge structure and excess mucus secretion (Figure 1.5) under laboratory condition than control one (Figure 1.3), while in field condition, appearance of damage was comparatively less in epithelial cells (Figure 1.6). Transmission electron microscopic observations of stomach showed severe deformed nuclei and mitochondria, vacuolation, damage in rough endoplasmic reticulum and dilated cell boundary under laboratory condition (Figure 1.8), while comparatively less damage were observed after glyphosate exposure, only appearance of large amount of heterogenous zymogen granules (Figure 1.9) compared to control one (Figure 1.7).

Likewise, stomach, intestine of control fish is also showing four histological layers (Figure 2.1). The mucosal villi of intestine showing prominent absorptive columnar epithelial cells with centrally placed nuclei. Mucous cells are observed all over the intestinal mucosa but no alterations were found (Figure 2.1). The most prominent lesions identified by light microscopic study in intestine of $A$. testudineus were degenerative changes in columnar epithelial cells and lamina propria, and disruption of blood vessel which led to damage in lamina propria under laboratory condition (Figure 2.2), but in field condition the extent of damage was comparatively less which included only secretion of mucus by exocytosis in some places of mucosal layer (Figure 2.3). 
Citation: Samanta P, Pal S, Mukherjee AK, Senapati T, Ghosh AR (2016) Histopathological and Ultrastructural Alterations in Anabas testudineus Exposed to Glyphosate-Based Herbicide, Excel Mera 71 under Field and Laboratory Conditions. J Aquac Res Development 7: 436. doi:10.4172/2155-9546.1000436
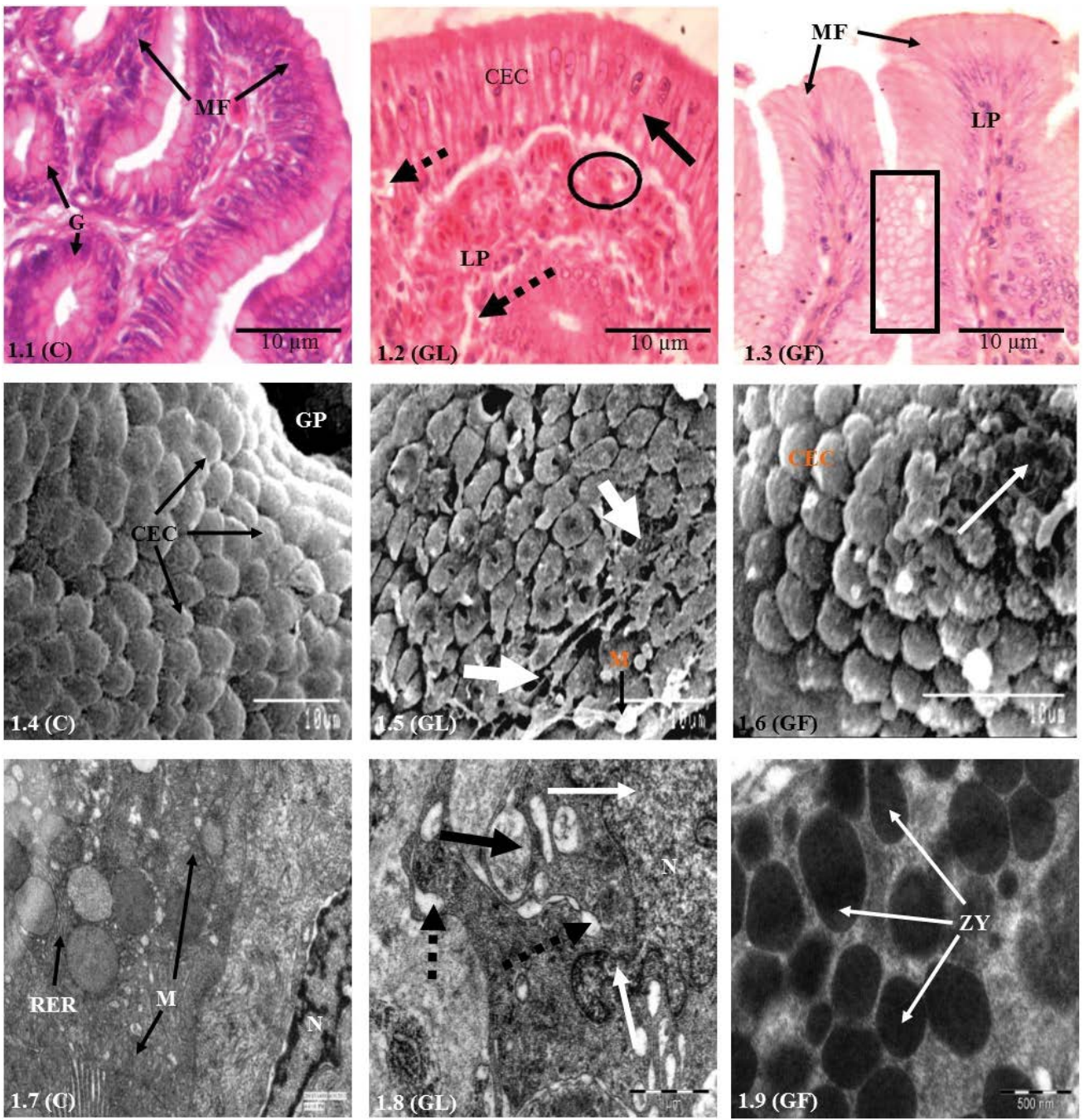

Figure 1: Histopathological photomicrographs of stomach of $A$. testudineus under control condition (C), glyphosate treated laboratory condition (GL), glyphosate treated field condition (GF). 1.1 (C) Showing normal structure and compact arrangement of columnar epithelial cells (CEC) of gastric mucosa with prominent nucleus under light microscopy (400x). 1.2 (GL) Showing vacuolation (broken arrow), damage in CEC (arrow), and damage in lamina propria (oval) (LP) under light microscopy (1000x). 1.3 (GF) Showing fusion of mucosal folds (square) under light microscopy (1000x). 1.4 (C) Scanning electron microscopy showing regular arrangement of mucosal folds (MF) with oval or round shaped columnar epithelial cells (CEC) and stubby microvilli (MV) (3000x). 1.5 (GL) Showing degenerative changes in columnar epithelial cells (bold arrow) under scanning electron microscopy (3000x). 1.6 (GF) Showing damage in CEC (arrow) under SEM (5000x). 1.7 (C) Stomach under transmission electron microscopy showing normal structure of gastric glands with abundant mitochondria (M) and rough endoplasmic reticulum (RER) (4000x). 1.8 (GL) Showing deformed nucleus (arrow) and mitochondria (bold arrow), damage in rough endoplasmic reticulum (square) and vacuolation (broken arrow) under TEM (6300x). 1.9 (GF) Showing heterogenous zymogen granules (ZY) under transmission electron microscopy (1000x).

SEM study in intestine also confirmed the severe damage in columnar epithelial cells and excess mucus secretion over columnar epithelial cells under laboratory condition (Figure 2.5), but in field condition, mucosal folds (Figure 2.4) and columnar epithelial cells did not show any significant alterations. The compactness of microvilli and contour of the columnar epithelial cells were very much distorted in laboratory condition than field (Figure 2.6). Transmission electron microscopic study of intestine showed dilation and fragmentation of endoplasmic reticulum, swelling of mitochondria and appearance of vacuolation after glyphosate exposure in the laboratory condition (Figure 2.8), while under field condition, intestinal epithelium of $A$. testudineus showed almost normal appearance of glycocalyx (Figure 2.7) and mitochondria, but in some mitochondria deformation was only noticed (Figure 2.9).
Studies on the sub-cellular, microscopic and ultramicroscopic characteristics through histological, scanning and transmission electron microscopic study of the gut epithelium of different teleosts were reported by a large number of authors [6-8,17], but study about the surface architecture, ultrastructural and mucosal modifications of the digestive tract namely stomach and intestine in Indian freshwater teleost, $A$. testudineus by exposure of glyphosate-based herbicide, Excel Mera 71 was not reported till date. Therefore, in the present study, an attempt has been made to evaluate the toxicity of this herbicide through histological and ultrastructural observations. In the present study, the marked pathological alterations of the luminal surface of the epithelial cells in stomach of $A$. testudineus were damage in gastric epithelium, which became elongated, vacuolated, and detached lamina propria from the epithelial layer. In the field condition, pathological alterations 
Citation: Samanta P, Pal S, Mukherjee AK, Senapati T, Ghosh AR (2016) Histopathological and Ultrastructural Alterations in Anabas testudineus Exposed to Glyphosate-Based Herbicide, Excel Mera 71 under Field and Laboratory Conditions. J Aquac Res Development 7: 436. doi:10.4172/2155-9546.1000436
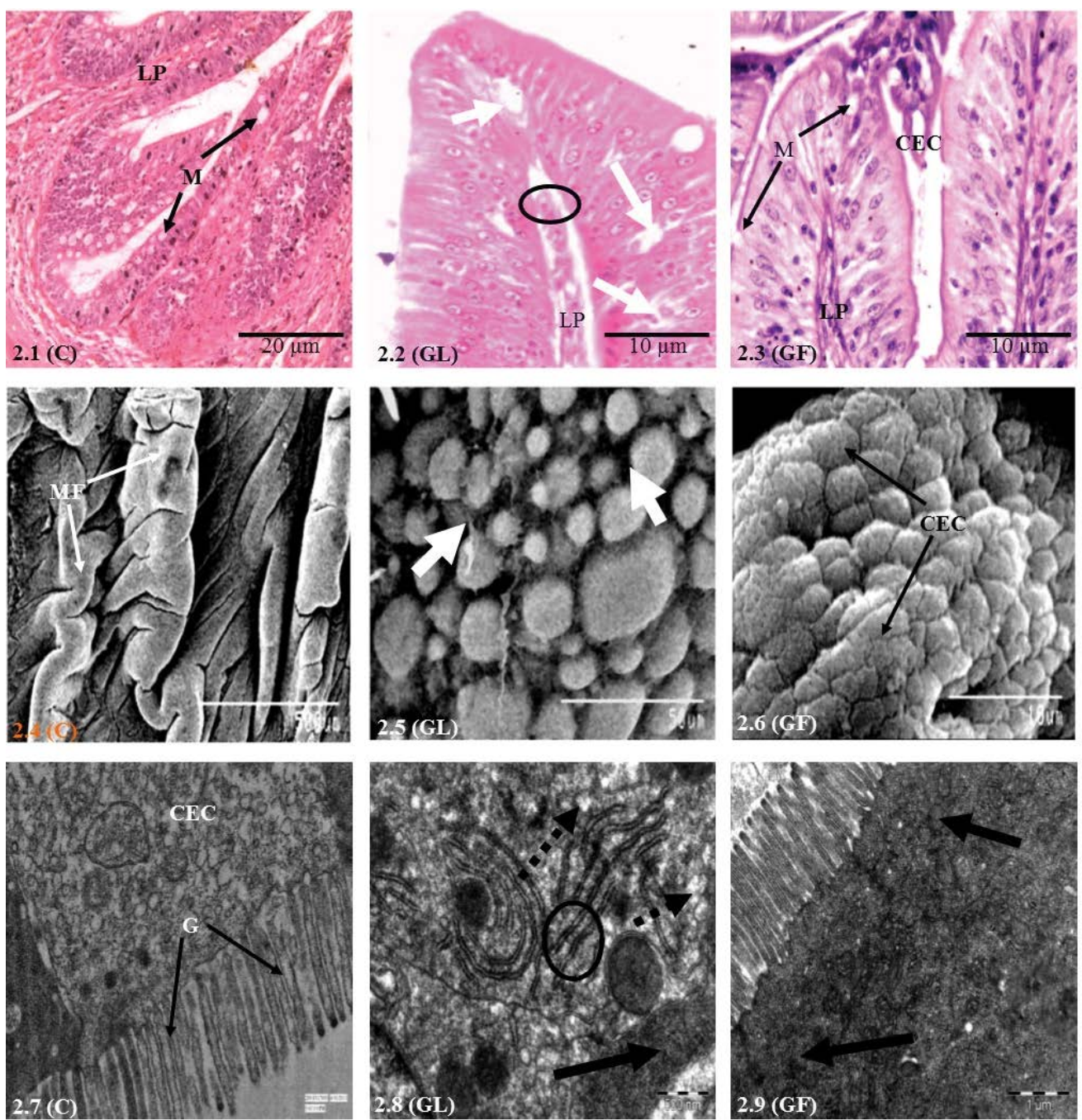

Figure 2: Histopathological photomicrographs of intestine of $A$. testudineus under control condition (C), glyphosate treated laboratory condition (GL), glyphosate treated field condition (GF). 2.1 (C) Showing normal appearance of lamina propria (LP), columnar epithelial cells (CEC) and mucus secretion (M) under light microscopy (1000x). 2.2 (GL) Showing degenerative changes in lamina propria (oval) and CEC (white arrow) with severe mucus secretion (M) under light microscopy (1000x). 2.3 (GF) Light microscopy showing almost normal structure of compactly arranged CEC with prominent nuclei (1000x). 2.4 (C) Showing normal appearance of mucosal folds (MF) with regularly packed oval or rounded CEC and prominent microvilli (MV) under scanning electron microscopy (100x). 2.5 (GL) Showing degenerative CEC (bold arrow) and excess secretion of mucus (M) under SEM observation (600x). 2.6 (GF) Showing normal mucosal folds (MF) (2000x). 2.7 (C) TEM observation showing normal appearance of columnar epithelial cells with glycocalyx (G) (7000x). 2.8 (GL) Showing vacuolation (broken arrow), dilated mitochondria (bold arrow), and dilated and fragmented endoplasmic reticulum (oval) under TEM (8000x). 2.9 (GF) TEM study showing normal appearance of CEC and glycocalyx (G) but deformed mitochondria (bold arrow) (5000x)

were very less than laboratory condition which included only partial fusion of mucosal folds. These alterations as seen under present study might interfere the normal functions of digestive glands and mucus secretion, which play a significant role in digestion of protein food materials and finally reduced the protection ability of gastric epithelial cells from chemical injuries and cell lysis. Distortion of digestive glands due to herbicidal toxicosis could hamper the production of digestive enzymes. Fusion of mucosal fold as seen under present study in field condition was also reported by Haloi et al. [18] in stomach of Channa punctatus after chronic exposure of endosulfan. Amminikutty and Rege [19] reported swelling, distortion and/or vacuolation with a tendency to necrotization in the mucosal epithelial cells of stomach of Gymnocorymbus ternitzi after chronic exposure of endosulfan and methyl ethyl mercurial. Severe vacuolations under present study was also reported by Ghanbahadur and Ghanbahadur [20] in stomach of larvivorous fish, Rasbora daniconius after endosulfan exposure. Ramírez-Duarte et al. [21] in their study observed mild hyperplasia in mucus cells of Piaractus brachypomus after Roundup exposure. The present study showed that glyphosate adversely affected the epithelial cells and caused fragmentation, excess mucus secretion on apical surface of the columnar epithelial cells and damage in the microridge structure in laboratory condition under SEM observation, while comparatively less damage only in epithelial cells was observed under field condition. Microridge structures on the epithelial cells play a significant role in anchoring thin mucus film over the soft mucous membrane and this mucus film lubricates the ingested food in these regions. Thus, it helps to overcome the trauma resulting from ingested material and protects the mucosa layer from mechanical rubbing [22]. In the present study, fragmentation of columnar epithelial cells and severe mucus secretion was found in epithelial surface of stomach. Excessive secretion of 
Citation: Samanta P, Pal S, Mukherjee AK, Senapati T, Ghosh AR (2016) Histopathological and Ultrastructural Alterations in Anabas testudineus Exposed to Glyphosate-Based Herbicide, Excel Mera 71 under Field and Laboratory Conditions. J Aquac Res Development 7: 436. doi:10.4172/2155-9546.1000436

Page 5 of 6

mucus from gastric epithelium indicated that glyphosate exposure triggers the activity of the aforesaid cells and ultimately reduced the protection ability of gastric epithelium from chemical injuries and cell lysis. Similar pathological lesions in Notopterus notopterus after arsenic exposure were reported through scanning electron microscope (SEM) by Ghosh and Chakrabarti [23] and by Bose [24] in A. testudineus after lead and cadmium treatment. Senapati et al. [25] also reported similar type of pathological alterations in alimentary canal of Channa punctatus after glyphosate exposure. Under transmission electron microscopic observations, the most notable changes in gastric epithelium of stomach in A. testudineus were severe deformed nucleus and mitochondria, vacuolation, damage in rough endoplasmic reticulum and dilated cell boundary in the laboratory condition after glyphosate exposure. In the field condition, comparatively less damage were observed in stomach after glyphosate exposure and these included appearance of large amount of heterogenous zymogen granules. Rebolledo and Vial [26] also reported similar results like present study. On the other hand, Carrassón et al. [27] in their study reported abundant smooth endoplasmic reticulum, mitochondria, rough endoplasmic reticulum, tubule-vascular network and heterochromatinic nucleus in stomach of Dentex dentex.

Intestine is the second most important part of fish alimentary canal and plays a vital role in digestion and absorption of food materials. It is exposed to different types of toxic substances directly via ingestion of contaminated food stuffs or indirectly via blood and/or lymph. Therefore, intestine can serve as a potent biomarker as well as sensitive organ for assessing toxicity of xenobiotic compounds in fish [28]. In the present study, the intestine of $A$. testudineus after glyphosate exposure showed marked histopathological lesions in laboratory condition like degenerative changes in columnar epithelial cells and disruption of blood vessel, while under field condition, the changes were not severe as in laboratory condition such as excessive secretion of mucus and damage in columnar epithelial cells in some places of mucosal layer. Less pathological lesions in intestine of A. testudineus in the field condition may be due to dilution effect, natural ambient habitat and rapid natural degradation of the herbicide, glyphosate. Disruption of blood vessels as observed under the study led to damage in lamina propria of the concerned fish. Mandal and Kulshrestha [29] also reported similar type of histopathological alterations in intestine of Clarias batrachus after sumithion exposure under laboratory condition. Sharma et al. [30] also observed similar types of histological alterations in intestine of Cirrhinus mrigala after pesticide exposure. On the contrary, Bose [24] reported degenerative columnar epithelial cells and severe mucus secretion in intestine of $A$. testudineus after lead exposure. These alterations in histological layers of intestine as seen under present investigation may deteriorate the production of digestive enzymes into gastric lumen, which ultimately affects the digestion of food stuffs and subsequent transfer of it to the next region in concerned fish. Disruption of blood vessels of the intestinal villi after herbicide intoxication reduces the process of absorption of essential macromolecules from lumen to tissue interior [31]. Under scanning electron microscopic observations, the mucosal folds of $A$. testudineus after glyphosate exposure in laboratory condition revealed severe damage in columnar epithelial cells and excess mucus secretion, while mucosal folds under field condition displayed no significant alterations as well as comparatively less damage. Damages as observed in the present study may be due to entering of the aforesaid herbicide into the alimentary tract of fish which induced mucus secretion throughout the length of the alimentary tract. Similar results were also observed through SEM investigation in Notopterus notopterus after arsenic exposure [23], in A. testudineus after lead and cadmium treatment [24] and in Channa punctatus due to toxicity of glyphosate herbicide [25]. The most conspicuous cytological alterations in intestine of $A$. testudineus in the laboratory condition seen under TEM study were dilation and fragmentation of endoplasmic reticulum, swelling of mitochondria and appearance of vacuolation; while in field condition almost normal appearance of mucosal folds of intestine was observed except deformation in some mitochondria. Damage to the intestinal mucosa of Channa punctatus after endosulfan has also been reported by Sastry and Siddiqui [32]. These alterations impair the intestinal transportation processes and evidenced by increased activity of different biochemical enzymes such as alkaline phosphatase and represents adaptive mechanism to protect the intestinal epithelium from the herbicidal attack. Considering the abovementioned alterations as observed in stomach and intestine, the severe responses under laboratory condition could be due to application of the high concentration which has enhanced the herbicidal toxicity. In the field condition, the influence of environmental parameters is higher and less toxic responses may be due to degradation in the field. Actually, the active ingredients are responsible for toxic condition to fish. In addition, glyphosate formulations are highly soluble in water; therefore, it is susceptible to leaching through the soil profile. Volatilization, photolysis, and oxidation aggravate the process of glyphosate dissipation and transformation into different metabolites [33]. Different responses in concerned fish tissues could be due to tissue-specific responses to herbicidal exposure. Less histopathological lesions in field condition after long-term exposure of herbicide may be due to lesser residual quantity in pond water.

\section{Conclusion}

In conclusion, the results clearly demonstrated that glyphosate used in agriculture causes changes in the histopathological and ultrastructural level of freshwater teleostean fish under field and laboratory conditions. The histopathological and ultrastructural alterations in stomach and intestine could be taken into consideration to monitor the herbicidal toxicity to fish under aquatic ecosystem and the impressions of alterations could be considered as biomarkers in assessing the fish health and aquatic ecosystems.

\section{Acknowledgement}

The authors like to thank the INSPIRE Program Division, Department of Science \& Technology, Govt. of India (DST/INSPIRE Fellowship/2011/164, Dt. 29.09.2011) for the financial assistance. We also like to thank the Head Department of Environmental Science, the University of Burdwan, Burdwan; West Bengal, India for providing the laboratory facilities and library facilities during the course of research. Authors are also thankful to the reviewers for improving the manuscript quality.

\section{References}

1. Rand GM (1995) Fundamentals of aquatic toxicology: effects, environmental fate and risk assessment. (2ndedn), Taylor \& Francis, Washington DC.

2. Reuters (2011) Roundup: cancer cause or crucial for food production? "The Huffington Post'.

3. Duke SO (1988) Glyphosate herbicides: Chemistry, degradation and mode of action, Marcel Dekker, New York.

4. Ruppel ML, Brightwell BB, Schaefer J, Marvel JT (1977) Metabolism and degradation of glyphosate in soil and water. J Agric Food Chem 25: 517-528.

5. USEPA (1993) EPA Reregistration eligibility decision (RED) facts glyphosate (EPA-738-F-93-011). United States Environmental Protection Agency, Washington DC.

6. Teh SJ, Adams SM, Hinton DE (1997) Histopathological biomarkers in feral freshwater fish populations exposed to different types of contaminant stress. Aquat Toxicol 37: 51-70. 
Citation: Samanta P, Pal S, Mukherjee AK, Senapati T, Ghosh AR (2016) Histopathological and Ultrastructural Alterations in Anabas testudineus Exposed to Glyphosate-Based Herbicide, Excel Mera 71 under Field and Laboratory Conditions. J Aquac Res Development 7: 436. doi:10.4172/2155-9546.1000436

7. Thophon S, Kruatrachue M, Upatham ES, Pokethitiyook P, Sahaphong S, et al. (2003) Histopathological alterations of white seabass, Lates calcarifer, in acute and subchronic cadmium exposure. Environ Pollut 121: 307-320.

8. Kasherwani D, Lodhi HS, Tiwari KJ, Shukla S, Sharma UD (2009) Cadmium toxicity to freshwater catfish, Heteropneustes fossilis (Bloch). Asian J Exp Sci 23: $149-156$

9. Fanta E, Rios FS, Romão S, Vianna ACC, Freiberger S (2003) Histopathology of the fish Corydoras paleatus contaminated with sublethal levels of organophosphorus in water and food. Ecotoxicol Environ Saf 54: 119-130.

10. Hinton DE, Lauren DJ (1990) Liver structural alterations accompanying chronic toxicity in fishes: potential biomarkers of exposure. Biomarkers of environmental contamination, Lewis, Boca Raton.

11. Jan MR, Shah J, Muhammad M, Ara B (2009) Glyphosate herbicide residue determination in samples of environmental importance using spectrophotometric method. J Hazard Mater 169: 742-745.

12. Chattopadhyay DN, Mohapatra BC, Adhikari S, Pani PC, Jena JK, et al. (2013) Effects of stocking density of Labeo rohita on survival, growth and production in cages. Aquacult Int 21: 19-29.

13. APHA, AWWA, WPCF (2005) Standard methods for the examination of water and wastewater. Washington, DC.

14. Weed Science Society of America (1994) Herbicide handbook. Weed Science Society of America, Champaign, IL.

15. Samanta P, Pal S, Mukherjee AK, Ghosh AR (2014b) Evaluation of metabolic enzymes in response to Excel Mera 71, a glyphosate-based herbicide and recovery pattern in freshwater teleostean fishes. BioMed Research Interanational.

16. Samanta P, Pal S, Mukherjee AK, Ghosh AR (2014c) Biochemical effects of glyphosate based herbicide, Excel Mera 71 on enzyme aactivities of acetylcholinesterase (AChE), lipid peroxidation (LPO), catalase (CAT), glutathione-S-transferase (GST) and protein content on teleostean fishes. Ecotoxicol Environ Saf 107: 120-125.

17. Biagini FR, David JAO, Fontanetti CS (2009) The use of histological histochemical and ultramorphological techniques to detect gill alterations in Oreochromis niloticus reared in treated polluted waters. Micron 40: 839-844.

18. Haloi K, Kalita M, Nath R (2013) The study on the histopathological changes of stomach of Channa punctatus (Bloch). By used pesticide endosulfan. Global Journal of Science Frontier Research Biological Sciences 13

19. Amminikutty CK, Rege MS (1977) Effects of acute and chronic exposure to pesticides Thiodan EC 35 and Agallot 3 on the liver of widow tetra Gymnococrymbus ternetzi (Boulenger). Indian J Exp Biol 15: 197-200.
20. Ghanbahadur A Ghanbahadur G (2012) Histopathological effect of organochloride endosulfan on intestine and stomach of larvivorous fish Rasbora daniconius. DAV Intl J Sci 1: 126-127.

21. Ramírez-Duarte WF, Rondón-Barragán LS, Eslava-Mocha PR (2008) Acute toxicity and histopathological alterations of Roundup $®$ herbicide on "cachama blanca" (Piaractus brachypomus). Pesq Vet Bras 28: 547-554.

22. Sinha GM, Chakrabarti $P$ (1986) Scanning electron microscopic studies on the digestive tract in the Mystus aor (Ham.). Proc Indian Natn Sci Acad 52: 267 273.

23. Ghosh AR, Chakrabarti P (2001) Impact of inorganic arsenic on mucosal surface of stomach, intestine and intestinal caeca of Notopterus notopterus (Pallas). ICIPACT 469-473.

24. Bose R (2005) Effects of lead and cadmium on the digestive system and kidney of Indian fresh water perch, Anabas testudineus (Cuvier) and subsequent recovery by EDTA. PhD Thesis, The University of Burdwan.

25. Senapati T, Mukherjee AK, Ghosh AR (2009) Observations on the effect of glyphosate based herbicide on ultrastructure (SEM) and enzymatic activity in different regions of alimentary canal and gill of Channa punctatus (Bloch). Journal of Crop and Weed 5: 236-245.

26. Rebolledo IM, Vial JD (1979) Fine structure of the oxynticopeptic cell in the gastric glands of elasmobranch species (Halaelurus chilensis). Anat Rec 193 805-822.

27. Carrassón M, Grau A Dopazo LR Crespo S (2006) A histological, histochemical and ultrastructural study of the digestive tract of Dentex dentex (Pisces, Sparidae). Histol Histopathol 21: 579-593.

28. Muniyan M (1999) Effect of ethofennprox (trebon) on the biochemical and histological changes in the selected tissues of the freshwater fish, Oreochromis mossambicus (Peters). PhD Thesis, Annamalai University.

29. Mandal PK, Kulshrestha H (1980) Histopathological changes induced by the sublethal sumithion in Clarias batrachus (Linn.). Indian J Exp Biol 18: 547-552.

30. Sharma RR, Pandey AK, Shukla GR (2001) Histopathological alterations in fish tissues induced by pesticides toxicity. Aquaculture 2: 31-43.

31. Ghosh AR (1991) Arsenic and cadmium toxicity in the alimentary canal and digestion of two Indian air-breathing teleosts Notopterus notopterus (Pallas) and Heteropneustes fossilis (Bloch). PhD Thesis, The University of Burdwan.

32. Sastry KV, Siddiqui AA (1982) Effect of endosulfan and quinalphos on intestina absorption of glucose in the freshwater murrel, Channa punctatus. Toxicol Lett 12: $289-293$.

33. Giesy JP, Dobson S, Solomon KR (2000) Ecotoxicological risk assessment for Roundup herbicide. Rev Env Contam Toxicol 167: 35-120. 